\title{
FormaÇÃo CONTINUADA DE PROFESSORES QUE ENSINAM MATEMÁTICA NO PRIMEIRO CICLO: ANÁLISE DE UMA PROPOSTA IMPlementadA No Estado DE MATo GROSSO
}

\author{
CONTINUED TRAINING OF TEACHERS WHO TEACH MATHEMATICS OF THE \\ FIRST CYCLE: ANALYSIS OF A PROPOSAL IMPLEMENTS IN THE STATE OF \\ MATO GROSSO
}

DOI: http://dx.doi.org/10.23926/RPD.2526-2149.2019.v4.n2.p499-513.id557

Lenir Tomazeli

Mestre em Educação

(UFMT)

Professora da SEDUC-MT

lenirtomazeli@gmail.com

\section{Rute Cristina \\ Domingos da Palma}

Doutora em Educação

(UNICAMP)

Professora da UFMT

rutecristinad@gmail.com
Resumo: Este artigo tem como objeto de estudo a formação continuada de professores, especificamente a política de formação continuada do Estado de Mato Grosso, e busca responder a questão: como o Projeto de Estudo e Intervenção Pedagógica (PEIP) foi concebido, desenvolvido e avaliado por professores que ensinam matemática no primeiro ciclo em uma escola estadual do município de Cáceres-MT?. Do estudo de caso qualitativo participaram cinco professoras alfabetizadoras do primeiro ciclo. As informações foram produzidas a partir de entrevistas individuais e coletivas e das anotações do caderno de campo. Conclui-se que a proposta desconsiderou as necessidades formativas dos docentes, vinculou o PEIP à Avaliação Diagnóstica do Ensino Público Estadual de Mato Grosso (ADEPE-MT), cujos resultados não foram reconhecidos pelos professores e instituiu uma dinâmica que não favoreceu o desenvolvimento docente e institucional.

Palavras-chave: Formação continuada; Anos iniciais; Matemática.

\begin{abstract}
This article aims at object of study the continued training of teachers, specifically the policy of continued training in the state of Mato Grosso who want to respond the question: "how the Projeto de Estudo e Intervenção Pedagógica (PEIP) was construed, developed and evaluated by teachers who teach mathematics in the first cycle in a public School at the municipality of Cáceres-MT? Of the research participated five literacy teachers of the first cycle, that participated in the formation. The data was produced from the individually and collectively interviews, and the notes in the field notebook. The results indicate that the proposal disregarded the formative needs of the teachers, linked the PEIP to the diagnostic evaluation of the public education from Mato Grosso (ADEPE-MT), whose results was unacknowledge by teachers and established a dynamics did not favour the faculty development and institutional.

Keywords: Continued Training; Early basic education; Mathematics.
\end{abstract}




\section{INTRODUÇÃO}

Muito tem se discutido sobre a importância da formação continuada para o desenvolvimento profissional docente, tomando dentre outros princípios, o necessário aprofundamento teórico-metodológico, a reflexão na prática e também sobre ela, além da autonomia e do trabalho colaborativo nas instituições educativas.

Em Mato Grosso, em 2016, a Secretaria de Educação do Estado (SEDUC-MT) instituiu uma proposta de formação substituindo o Projeto Sala de Educador (PSE), implantado em 2003, pelo Projeto de Estudo e Intervenção Pedagógica (PEIP) ${ }^{\mathbf{1}}$, destinado aos docentes.

O PEIP teve como objeto a formação de professores e apresentou como previsão de atividades a realização de estudos, planejamento e desenvolvimento de projetos de intervenção pedagógica que deveriam ter foco na análise de necessidades de aprendizagem dos estudantes, detectadas em avaliações externas e internas, visando a superação das dificuldades diagnosticadas.

Diante desse contexto, a pesquisa de estudo de caso qualitativo visou compreender como o PEIP foi concebido, desenvolvido e avaliado por professores que ensinam matemática no primeiro ciclo em uma escola estadual do município de Cáceres-MT. Para situar o objeto de estudo tratamos, a seguir, de contextualizar brevemente em que momento o PEIP foi proposto às unidades escolares do estado de Mato Grosso.

\section{Políticas de formação continuada em Mato Grosso: do Projeto sala de EDUCADOR AO PROJETO DE ESTUDO E INTERVENÇÃO PEDAGÓGICA}

É unanime entre pesquisadores que investigam a formação de professores (IMBERNÓN, 2010; DINIZ-PEREIRA, 2019; GATTI, BARRETO, 2009) a importância da formação continuada para o desenvolvimento profissional.

Em seus estudos Gatti e Barreto (2009) ressaltam que a ideia de formação continuada como "desenvolvimento profissional é a base de dois modelos amplamente aceitos e defendidos na literatura educacional mais recente: as oficinas de reflexão sobre a prática e a formação centrada no fortalecimento institucional". Neste caso, as autoras alertam que o fortalecimento da escola e as práticas reflexivas necessitam de "envolvimento dos professores, de um ambiente propício a realização de trabalho, onde haja coletividade, gestão participativa e recursos necessários". (GATTI; BARRETO, 2009, p. 203).

\footnotetext{
${ }^{1}$ O PEIP foi instituído pela Portaria 161/2016/GS/SEDUC-MT, publicada em Diário Oficial no dia 14 de abril de 2016.
} 
No Estado de Mato Grosso, os professores que atuam no primeiro ciclo da rede estadual, além da participação em formações em rede, específicas para a alfabetização, promovidas pelo Ministério da Educação e Cultural (MEC) nos últimos anos, como o ${ }^{2}$ PRO-LETRAMENTO e Programa Nacional de Alfabetização na Idade Certa (PNAIC), participam também da formação continuada desenvolvida na escola, a partir de orientações da SEDUC-MT.

Com a finalidade de desenvolvimento da formação continuada de todos os profissionais da educação que estavam em serviço nas escolas da rede estadual de ensino em Mato Grosso, em 2003 instituiu-se o Projeto Sala de Professor, depois, intitulado em 2009 como Projeto Sala de Educador (PSE). Nos anos em que ocorreram o PSE a SEDUC-MT publicava em diário oficial, no início do ano letivo, documentos orientativos que direcionavam as escolas para uma prática de formação continuada mais autônoma, uma vez que o grupo de profissionais de cada escola escolhiam as temáticas que pretendiam estudar no decorrer do ano, o período, a dinâmica e elaboravam o projeto de formação continuada de acordo com suas necessidades. Em 2016, o Projeto Sala do Educador foi substituído pelo PEIP.

O documento orientativo sinalizava que o PEIP deveria ser composto de três macro ações, a saber (Mato Grosso, 2016, p. 42-43):

- Ação 1 - Estudos Gerais;

- Ação 2 - Planejamento da Intervenção Pedagógica;

- Ação 3 - Intervenção (na regência), estudos específicos e socialização.

Para a realização da ação 1 foram indicados textos para leitura que tratavam das temáticas: projetos de intervenção, avaliação e pesquisa-ação.

A referida portaria, em seu Artigo $3^{\circ}, \S 2^{\circ}$ destacava que "Os estudos, as pesquisas e os projetos de intervenções pedagógicas deverão ter o foco na análise de necessidades de aprendizagem dos estudantes, para superar as dificuldades diagnosticadas ou potencializar a aprendizagem discente", e para isso determinou que o PEIP fosse produzido a partir da análise dos resultados da ADEPE-MT, das avaliações das disciplinas do currículo, das avaliações internas e do diagnóstico das necessidades formativas (MATO GROSSO, 2016, p. 42).

\footnotetext{
${ }^{2}$ Formação em rede destinada a todos os professores que atuavam nos anos iniciais do ensino fundamental das escolas das redes municipais e estaduais, que visavam a melhoria do processo ensino-aprendizagem da língua portuguesa e matemática. O programa Pró-Letramento foi realizado entre 2005 e 2009, e o Pacto Nacional pela Alfabetização na Idade Certa no período de 2013 a 2018.
} 
Para isso, em 2016, a SEDUC-MT formou parceria com o Centro de Políticas Públicas e Avaliação da Educação da Universidade de Juiz de Fora (CAED/UFJF), instituição privada, para avaliarem os estudantes do Ensino Fundamental e Médio da rede estadual, através da ADEPE-MT, cujo objetivo era "contribuir para a elaboração e proposição de ações de melhoria da qualidade de educação ofertada pelas redes públicas de ensino do Mato Grosso" (ADEPEMT, 2016, p. 5).

Com a parceria firmada entre a SEDUC-MT e a CAED, a educação pública em Mato Grosso caminhou para uma nova estruturação. Segundo Costa, Gentil e Amaral (2016, p. 15):

[...] está em curso a desestruturação da educação pública no Estado por meio da desconstrução das políticas democráticas e participativas já conquistadas e sua substituição por políticas de caráter gerencialista, que vem cristalizando a ideia de educação como mercadoria e de minimização da responsabilidade do Estado para com o que deveria ser público.

O primeiro passo diante dessa mudança foi criar o Núcleo de Avaliação, Investigação e Análise de Dados Educacionais (NAIADE) para coordenar as ações relacionadas às avaliações e orientar os rumos do sistema de ensino em Mato Grosso, na medida em que a ADEPE-MT serviria de base para a formação continuada dos profissionais da rede estadual em 2016.

Como dito, nossa intenção foi compreender como o processo formativo PEIP se desencadeou e como as professoras do primeiro ciclo se inseriram nesse contexto, especificamente no que diz respeito às ações que envolveram a área da matemática. Desta forma, apresentaremos na próxima seção uma discussão sobre os processos de ensino e aprendizagem da matemática no primeiro ciclo.

\subsection{SOBRE APRENDER E ENSINAR MATEMÁTICA NO PRIMEIRO CICLO}

Os momentos destinados à formação continuada podem contribuir para o processo de estudo, de reflexão sobre as práticas pedagógicas e discussão entre os pares, na busca de alternativas para a solução de problemas encontrados no cotidiano da sala de aula, mobilizando assim, mudanças necessárias no ensino da matemática.

A partir desse entendimento, concordamos com Fiorentini (1995, p. 29) quando afirma que:

\footnotetext{
O processo de construção de um ideário pedagógico, tanto individual como coletivo, é sempre dinâmico e dialético. De fato, se estamos permanentemente refletindo sobre nossa prática pedagógica, se discutimos com nossos pares, se pesquisamos e buscamos continuamente novas fontes teóricas e novas alternativas de ação em sala de aula, ... então, é de se esperar que nosso ideário também esteja em permanente mutação.
}

Assim, enfrentar coletivamente o desafio que é ensinar matemática nos anos iniciais pode trazer melhorias para o processo ensino-aprendizagem, partindo do pressuposto de que há 
necessidade de se considerar tanto as especificidades das crianças, como as finalidades do ensino da matemática no primeiro ciclo.

Moretti (2015), ao se basear nas ideias de Moura (2002), apresenta o desenvolvimento desse processo nos anos iniciais do Ensino Fundamental:

\begin{abstract}
No ensino da matemática, o conhecimento sobre a história da produção do conceito (as necessidades que o motivam, as soluções encontradas para responder a essa necessidade, suas contradições e seus impasses) permite que os professores proponham situações de ensino que coloquem para as crianças necessidades análogas, o que não significa reproduzir o seu contexto histórico de produção. (MORETTI, 2015, p. 26).
\end{abstract}

Assim, criar situações em que as crianças necessitem pensar matematicamente, registrar e comunicar suas ideias pode desencadear motivações e promover a aprendizagem significativa. Nesse sentido, Moretti (2015, p. 28) afirma que "do ponto de vista das tarefas atribuídas aos professores, organizar o ensino para o desenvolvimento dos conceitos científicos nas crianças é um importante compromisso de sua prática pedagógica, o que demanda a organização intencional das ações. [...]”.

O exposto até aqui nos leva a refletir sobre a grande responsabilidade do professor que atua no primeiro ciclo para a aprendizagem da matemática. Como afirma Moura $(2011$, p. 8):

[...] Ao compreender um conceito o sujeito se apropria de um conjunto de regras e signos que o capacita para lidar com os outros conceitos em uma rede de conhecimento que lhe permite ir para um outro nível de compreensão do conhecimento disponível no seu meio cultural [...].

A matemática, se ensinada de forma significativa, exercerá função primordial no desenvolvimento pleno da criança que frequenta o primeiro ciclo. É preciso reafirmar que, para a melhoria do ensino-aprendizagem da matemática na escola é fundamental investir no estudo dos conceitos matemáticos e de como a criança aprende, nos momentos de reflexões e trocas de experiências, e a formação continuada pode favorecer esse movimento formativo. É fundamental criar situações na escola em que os professores tenham a oportunidade de discutir com seus pares sobre suas concepções de matemática e suas práticas pedagógicas, a fim de propiciar a melhoria no processo de ensino e, em consequência, favorecer a aprendizagem das crianças.

\title{
3 Metodologia da Pesquisa
}

Para a realização desta pesquisa fizemos a opção por uma abordagem qualitativa do tipo estudo de caso. Para Stake (2012) um caso é estudado

quando ele próprio se reveste de um interesse muito especial, e então procuramos o pormenor da interação com os seus contextos. O estudo de caso é o estudo da 
particularidade e complexidade de um único caso, conseguindo compreender a sua atividade no âmbito de circunstâncias importantes. (STAKE, 2012, p. 11).

O caso que propomos investigar se refere à formação continuada PEIP, apresentada aos professores da escola pesquisada, elaborada pela SEDUC-MT, na visão das professoras que ensinam matemática no primeiro ciclo em uma escola estadual do município de Cáceres-MT. A pesquisa foi realizada no período de julho a dezembro de 2016 em uma escola estadual, por nós identificada como escola Gemas, do município de Cáceres-MT, com um grupo composto por cinco professoras alfabetizadoras que atuavam no primeiro ciclo, sendo uma professora do primeiro ano, duas do segundo ano e duas do terceiro ano, as quais optamos por denominá-las respectivamente, por Rubi, Pérola, Esmeralda, Ágata e Jade. Também contribuíram com a pesquisa dois coordenadores pedagógicos, responsáveis pela formação continuada na escola Gemas, identificados como Topázio e Turquesa.

As informações apresentadas no texto são oriundas das anotações observadas e das impressões registradas no caderno de campo da pesquisadora (CCP), além de entrevistas individuais (EI) e entrevista coletiva (EC) realizadas no decorrer de um semestre letivo com os participantes da pesquisa.

No processo da análise procuramos triangular as informações na tentativa de identificar "se o que estamos a observar e a relatar transmite o mesmo significado quando descoberto em circunstâncias diferentes" (STAKE, 2012, p. 126), organizando-as em três eixos temáticos: a dinâmica da etapa de estudos coletivos na escola Gemas; como as professoras conceberam, desenvolveram e avaliaram a formação continuada PEIP e as percepções das professoras sobre a avaliação externa ADEPE e internas no PEIP.

\section{FormaÇÃo CONTINUAda de PROFESSORAS QUE ENSINAM MATEMÁTICA NO PRIMEIRO CICLO NO PEIP}

Nesta seção, pretendemos responder como o PEIP foi concebido, desenvolvido e avaliado por professoras que ensinavam matemática no primeiro ciclo em uma escola estadual do município de Cáceres-MT, a partir dos três eixos temáticos.

\subsection{A DinÂMICA DA ETAPA DE ESTUdOS COLETIVOS NA ESCOLA GEMAS}

Para entendermos as percepções das professoras sobre o PEIP buscamos saber como foi a dinâmica da formação, a escolha das temáticas, a frequência, a condução dos encontros e o curso GeoGebra, de modo a explicar o contexto, para assim entender a avaliação das professoras referente à formação continuada desenvolvida. 
A formação continuada na rede estadual de Mato Grosso, em 2016, foi totalmente direcionada pela SEDUC-MT, que definiu as temáticas e os textos para a etapa de estudos na portaria 161/2016/SEDUC-MT.

Ao comentar sobre como se deu o início da formação continuada - PEIP - na escola Gemas, o coordenador Topázio, responsável pela formação, iniciou sua fala criticando a atitude de imposição da SEDUC-MT, “[...] Não houve uma discussão, nós não sentamos para debater, porque o projeto estava elaborado e a gente tinha apenas que executar [...] ” (EI, TOPÁZIO, coordenador).

Como vimos, a participação da escola e dos professores na etapa inicial do PEIP foi apenas a de executar o que foi determinado pela SEDUC-MT. Acreditamos que o importante não é apenas a existência da formação continuada na escola, mas, sobretudo, a forma como o processo formativo é proposto. Concordamos com Day (2001, p. 17), quando afirma que é vital que os professores "participem activamente na tomada de decisões sobre o sentido e os processos da sua própria aprendizagem" e que o desenvolvimento profissional "ao longo da carreira é uma responsabilidade conjunta dos professores, das escolas e do Governo".

$\mathrm{Na}$ escola Gemas os encontros aconteciam todas as terças-feiras, com os professores divididos em dois grupos, em turnos opostos ao período que lecionavam. As colaboradoras da nossa pesquisa participavam dos encontros realizados no período matutino.

No PEIP, a frequência do professor na formação tornou-se obrigatória, sob ameaça de desconto em folha de pagamento. Em relação à frequência e carga horária, o documento da SEDUC-MT explicita que:

\footnotetext{
A carga horária para a formação e desenvolvimento profissional é de 04 (quatro) horas semanais, previstas nas dez horas atividades que computam, com as 20 (vinte) horas da regência, a jornada de trabalho de 30 (trinta) horas semanais, em conformidade com a Lei 050/1998. (MATO GROSSO, 2016, p. 46).
}

O documento destaca ainda que, "para efeito de certificação, serão computadas as horas efetivamente cumpridas no PEIP com a formação e o desenvolvimento profissional, de acordo com o cronograma elaborado pela escola com o monitoramento do Centro de Formação de Professores - CEFAPRO” (MATO GROSSO, 2016, p.42-43).

Estão implícitas, na citação acima, duas formas de obrigar os professores a frequentarem a formação continuada na escola: a certificação e a ameaça do desconto em pagamento em caso de ausência. Entendemos que essa atitude faz com que haja uma distância cada vez maior entre o que leva os professores a participarem da formação e a real necessidade da formação continuada. 
Em relação à condução dos encontros formativos na escola Gemas, Topázio conta como preparava e desenvolvia, "então eu preparava tudo isso em slides e colocava para o professor, expunha, passava vídeo, buscava fotos, analogias, comparações, e depois ao final de tudo isso, a gente sentava e discutia. [...]". Pelo relato do coordenador, podemos constatar que a formação era realizada em forma de palestra. O coordenador justifica sua decisão explicitando:

\begin{abstract}
Nós decidimos fazer esse trabalho mais expositivo para não sobrecarregar o professor porque se a gente distribui o texto, trabalha o texto, esse professor leva para casa e prepara. Primeiro eu acredito, e os colegas acreditavam também, que a atividade não era a mesma, era mais desgastante para o colega. Então a gente discutia naquele momento, expunha o material, ficava menos desgastante, menos cansativo e menos maçante também. (EI, TOPÁZIO, coordenador).
\end{abstract}

Apesar das boas intenções do coordenador, que era não "sobrecarregar" o professor, este foi criticado pelas professoras por elas não terem tido acesso aos textos da formação.

No segundo semestre a dinâmica da formação foi alterada e as professoras foram convidadas a participar de um curso de GeoGebra ${ }^{3}$. As docentes Rubi, Ágata e Jade não conseguiram perceber a possibilidade de uso deste software nas turmas em que lecionavam e avaliam que o curso deveria ter sido direcionado para os anos iniciais do ensino fundamental.

Jade: Foi assim, eles vieram, perguntaram se a gente tinha interesse em fazer esse cursinho com eles. Só que nós esperávamos que fosse mais voltado para nossa realidade. Ele falou que seria.

Rubi: Eu gostei. Até já instalei no meu computador, porque se eu for ficar com o quarto ano vai dar para usar.

Ágata: Então, é isso que eu ia falar, para quarto e quinto ano.

Jade: Até porque nós pedimos para ele se estaria voltado para o primeiro ciclo.

Rubi: Mas eu lembro, ele pediu primeiro ciclo. (EC, JADE, RUBI E ÁGATA)

Desta forma, o GeoGebra, que poderia ter sido uma ação interventiva para a superação das dificuldades dos alunos em matemática, não teve aceitação por parte das professoras participantes desta pesquisa que reagiram, conforme observamos na formação continuada, mantendo o silêncio, saindo várias vezes da sala nos momentos formativos, ou realizando outras atividades no mesmo período do curso.

Consideramos que uma ação formativa que possibilite a reflexão sobre os problemas da educação, sobre as causas desses problemas, com questões que emerjam das dificuldades enfrentadas nas escolas e dos problemas sociais que afetam diretamente o processo de ensinoaprendizagem, podem representar uma ameaça ao sistema político brasileiro. Isso porque a

\footnotetext{
${ }^{3} \mathrm{O}$ curso do Geogebra foi proposto como parte de uma pesquisa da Especialização de Ensino de Ciências e Matemática, desenvolvida pela Universidade Estadual de Mato Grosso (UNEMAT).
} 
formação continuada, como vinha sendo concebida nos últimos anos, estava mobilizando os professores a refletirem sobre "questões relacionadas a interdisciplinaridade, ciclo de desenvolvimento humano, ensino por projetos, as discussões sobre a diversidade étnico-racial na escola [...]" (GATTI; BARRETO, 2009, p. 20), temáticas essas que podem suscitar discussões e reinvindicações.

Enfim, constatamos que houve uma tentativa da SEDUC-MT de retomar o controle da formação continuada ao implantar o PEIP, pois indicou o que estudar, ao determinar as temáticas e os textos, o como e quando estudar, ao determinar as etapas sucessivas do PEIP.

\subsection{COMO AS PROFESSORAS CONCEBERAM, DESENVOLVERAM E AVALIARAM O PROJETO de Estudo e Intervenção Pedagógica}

No segundo eixo, interpretamos que os dados revelaram que a formação continuada foi concebida pelas professoras como uma formação de cunho apenas técnico (IMBERNÓN, 2010). Constatamos essa característica ao considerar que o PEIP:

a) Não respeitou o contexto da escola nem as especificidades do ciclo da alfabetização. A professora Ágata, assim como as demais professoras, afirma que a formação continuada se "distanciou mais ainda de atender a realidade da sala de aula e da escola” e não atendeu as necessidades da escola e do grupo. Segundo a professora

Quando há uma discussão em um grupo pequeno, e é local, e se discuti coisas da escola é mais produtivo, tanto para as professoras dos três anos iniciais, quanto para a escola determinar: - Ah! Então vamos trazer alguém lá da matemática para trabalhar tal conteúdo no primeiro, no segundo e no terceiro ano. Aí, eu acho produtivo. (EC, ÁGATA - Prof. ${ }^{\text {a }} 2^{\circ}$ ano).

b) Ignorou os saberes docentes das professoras, porque, segundo Ágata:

Assim como para planejar uma aula é preciso conhecer os alunos, o nível de aprendizagem em que eles estão. A formação teria que ter esse critério também. Em que nível estão os professores, se são iniciantes, são recém-formados, se já tem uma bagagem. Porque acabou a gente revendo muitas coisas que a gente já viu, sem avançar. (EI1, ÁGATA - Prof. ${ }^{\mathbf{a}}{ }^{\mathbf{o}}$ ano).

c) Ignorou os problemas que enfrentam no cotidiano da sala de aula, conforme afirmaram Jade e Ágata,

Eu acho que tinha que olhar mais para escola em si. Ver onde é que o professor está pedindo socorro. Nós não tivemos isso. É muito mais vantajoso trabalhar as dificuldades que a gente tem do que está trazendo algo que não está... (silenciou). (EC, Prof ${ }^{\mathrm{a}}$. JADE - Prof ${ }^{\mathrm{a}} .1^{\mathrm{o}}$ ano).

Faltou atender a identidade do grupo de profissionais da escola. Eu acho que é isso, na nossa realidade, o nosso nível de formação, onde é que está a nossa carência, faltou determinar isso. Acompanhar a aprendizagem, onde é que o professor está precisando de ajuda, porque as vezes o olhar de fora é tão necessário. Faltou isso. E já veio excluído desde o início do ano, porque o PEIP já excluiu tudo isso, qual que é a 
identidade da escola. Veio que tinha que ser assim e pronto! Nós estamos entrando para um retrocesso histórico (EC, ÁGATA - Prof. ${ }^{a} 2^{\circ}$ ano).

d) Não possibilitou o protagonismo das professoras nas etapas do processo formativo, como relatado pelo coordenador responsável pela formação.

[...] quando se fala de Projeto PEIP, o projeto já está elaborado. Nós não temos que sentar com os professores ou com os coordenadores e fazer um projeto, escolher textos junto com os professores, ouvir opiniões, porque esse aí foi apresentado, foi proposto e nós seguimos a portaria. [...] (EI, TOPÁZIO, coordenador).

Para as professoras, a formação continuada deve ter relação com as práticas pedagógicas, com o contexto em que estão inseridas, para que possa ser útil. Suas falas nos remetem a Moretti (2007, p. 101) quando elucida que é "oscilando entre momentos de reflexão teórica e ação prática que o professor vai se constituindo”. Nesse sentido, consideramos que os apontamentos das professoras são relevantes e caminham ao encontro do que acreditamos ser necessário em uma formação continuada.

Desta forma, é importante que as formações levem em consideração aquilo que o professor diz, sente e, principalmente, o que o motiva a fazer uma formação continuada, o que necessita para avançar profissionalmente. Uma formação que auxilie o professor nas necessidades mais urgentes, no que se refere à aprendizagem dos alunos, um acompanhamento mais próximo, no sentido de colaborar para amenizar ou solucionar as dificuldades que os alunos possam apresentar na aprendizagem e os professores no ensino.

É fundamental que se compreenda que a formação deve atender às especificidades do grupo e respeitar o contexto. Segundo Imbernón (2010) a ideia central de se potencializar uma formação

[...] que seja capaz de estabelecer espaços de reflexão e participação, para que os professores aprendam com a reflexão e a análise das situações problemáticas dos cursos de formação de professores e para que partam das necessidades democráticas do coletivo, a fim de estabelecer um novo processo formador que possibilite o estudo da vida na sala de aula e nas instituições educacionais, os projetos de mudança e o trabalho colaborativo. (IMBERNÓN, 2010, p. 42)

Compreendemos que tudo isso denotou desrespeito com o tempo e esforços empenhados na realização da formação continuada, o que resultou em desmotivação, por parte das professoras, em participarem da formação continuada e fez com que a professora Rubi não considerasse sequer as ações desenvolvidas como formação continuada além de dizer: “[...] eu estava aqui cumprindo minha carga horária.” (EI, RUBI - Prof ${ }^{a} .3^{\circ}$ ano).

As palavras que destacamos a fim de resumir o sentimento que as professoras tiveram em relação ao desenvolvimento do PEIP são insatisfação, frustração, solidão, preocupação, decepção, desmotivação, cansaço, tristeza, entre outras, ou seja, sentimentos negativos que 
provocaram rejeição da formação continuada e que devem ser considerados para as próximas propostas de formação.

Outro ponto que destacamos e discutimos nesse eixo foram as dificuldades em relação às condições de trabalho no contexto escolar, destacadas nas falas das professoras que nos levaram a refletir sobre a tendência que considera que basta investir apenas na formação continuada dos professores para resolver todos os problemas que resultam na má qualidade da educação. Tal tendência responsabiliza apenas o professor pela não aprendizagem dos alunos e inculca na população esse pensamento, desvalorizando cada vez mais o profissional do ensino.

Nesse sentido, nos aproximamos da posição de Diniz-Pereira (2019, p. 71) quando destaca que, ao discutir a formação continuada,

[...] não poderíamos nos esquecer do princípio da indissociabilidade entre a formação e as condições adequadas para a realização do trabalho docente (salários dignos, maior autonomia profissional, dedicação exclusiva a uma única escola, pelo menos um terço da jornada de trabalho para planejamento, reflexão e sistematização da prática, estudos individuais e coletivos, salas de aula com um número reduzido de alunos)

Uma escola que não propicia as condições necessárias para a ação docente pouco pode contribuir para o seu desenvolvimento profissional.

Foram muitas as situações presenciadas por nós no decorrer desta pesquisa que consideramos percalços para a realização do PEIP, assim como de qualquer formação nesses moldes. Selecionamos a fala de Pérola, para ilustrar as condições objetivas vivenciadas na escola Gemas.

(...) muita coisa não dá para estar fazendo, devido à falta de dinheiro para comprar, porque depende de verba e a escola não tem. Até o ambiente onde trabalhamos é precário, porque as vezes nem ventilador para ventilar os alunos tem. Fiquei várias semanas ali, sem ventilador na sala de aula, estamos com as janelas abertas. Aí chega o diretor e fala, olha Pérola, nem tem papel para tirar xerox para os alunos. Eu tenho que usar o papel, porque o quadro eu não posso, se eu fechar a janela e fechar e as cortinas os alunos vão ficar padecendo aqui no calor, então tem que ficar com as janelas abertas e se ficar com as janelas abertas não dá para usar o quadro por causa do reflexo da luz, porque o quadro é de vidro, então ... (silenciou). (EI, PÉROLA Prof. ${ }^{\mathrm{a}}{ }^{\mathrm{o}}$ ano).

Acreditamos que, enquanto o sistema educativo continuar precário, devido à má utilização dos recursos destinados à educação, não há formação continuada que resolva o problema da qualidade do ensino. Não queremos aqui negar a importância da formação continuada, pelo contrário, ela é uma ação fundamental. Porém, não é com o modelo de formação continuada desenvolvido no PEIP que ocorrerá essa mudança.

Nesse contexto, consideramos que é preciso levar em conta o fortalecimento da escola na formação continuada, para que, de fato, a formação seja da escola, e não apenas uma 
formação realizada na escola. Para isso, Gatti e Barreto (2009, p. 203) indica que é preciso criar um ambiente que possibilite o "envolvimento dos professores, de um ambiente propício a realização de trabalho, onde haja coletividade, gestão participativa e recursos necessários”, pontos importantíssimos para uma formação continuada que acreditamos e que não foi possível ver durante o percurso formativo.

\subsection{PERCEPÇõES DAS PROFESSORAS SOBRE A AVALIAÇÃo EXTERNA ADEPE E INTERNAS NAS AÇÕES DO PEIP}

Como já dito, uma das ações a serem desenvolvidas na formação continuada PEIP era a análise de necessidades de aprendizagem dos estudantes, diagnosticadas através de avaliações externas e internas. No entanto, vimos que os resultados da avaliação ADEPE, realizada pelo CAED/UFJF, marcou um descompasso com as avaliações internas nas ações do PEIP, o que fez com que as professoras não estabelecessem nenhuma relação entre as duas avaliações, uma vez que o que foi ensinado difere do que foi avaliado e, com isso, as professoras tiveram dificuldades até mesmo no preenchimento do relatório avaliativo dos alunos.

É possível comparar a ADEPE e a avaliação realizada por Ágata no primeiro bimestre de 2016, para melhor compreensão desta diferença observada.

Figura 1 - Gráfico resultado avaliação ADEPE X Avaliação da aprendizagem da professora Ágata

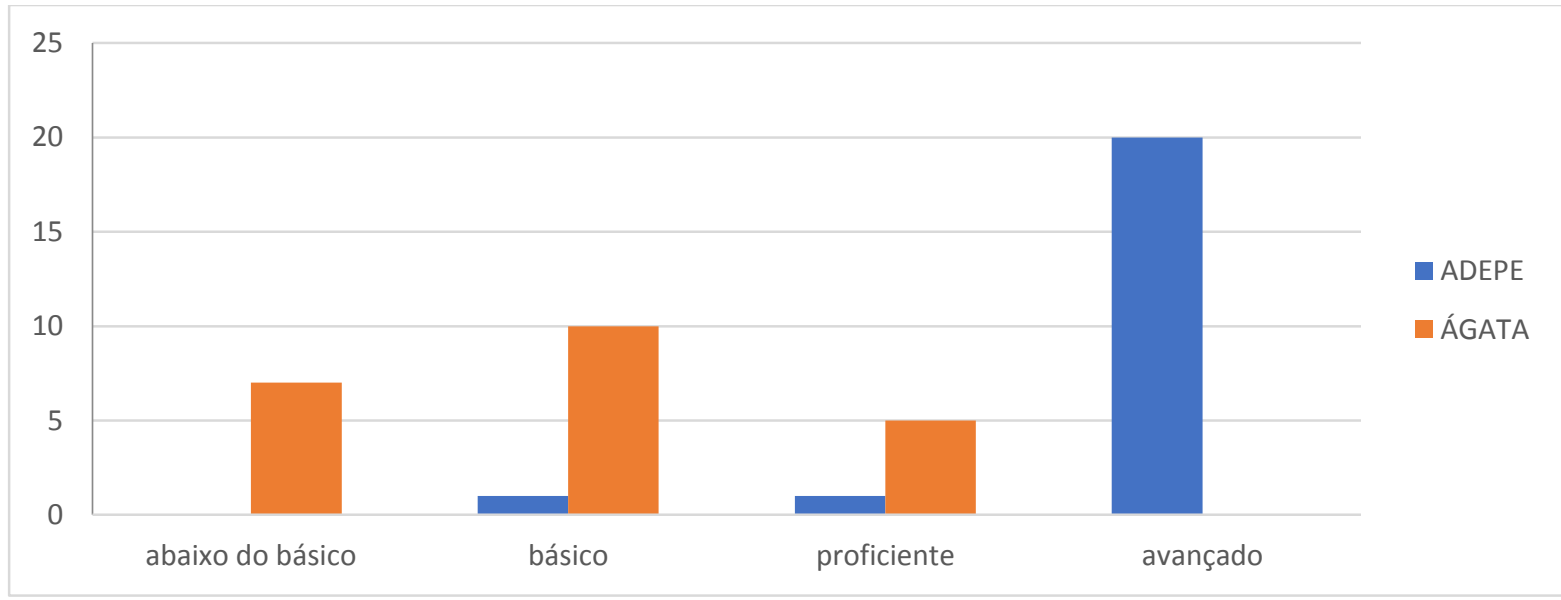

Fonte: Organizado pela pesquisadora (2017)

Os dados indicam uma disparidade entre os resultados. Os resultados da ADEPE apresentam informações de que os alunos estão em um nível bem avançado na aprendizagem e Ágata tem em mãos uma realidade completamente diferente. Pelos resultados da ADEPE não há necessidade de um plano de intervenção pedagógica para essa turma.

Com intenção de discutir como as professoras relacionaram as duas avaliações apresentamos o posicionamento das professoras Rubi, Ágata e Pérola. 
Nem sempre os alunos que sabem vão bem nas provas [...] Eu percebi que os alunos que fazem as atividades, que eu sei que sabem, não foram muito bem. Parece que eles têm uma barreira quando falam que é avaliação. (EI, RUBI - Prof. ${ }^{\text {a }} 3^{\circ}$ ano).

A do Estado eu fiquei bem frustrada com ela. Porque alunos que não sabem nem o A, foram muito bem na provinha do Estado e alunos que sabem ler com mais facilidade não foram tão bem. Os resultados não coincidiram com as avaliações diárias que faço com os alunos (EI, ÁGATA - Prof. ${ }^{\text {a }} 2^{\circ}$ ano).

Não, não condiz. Eles marcam $X$, marcam $X$, marcam $X$... eu tive um aluno que marcou quase tudo certo e é aluno que tem dificuldade, tanto na matemática quanto no português (EI, PÉROLA - Prof. ${ }^{\mathrm{a}} 2^{\circ}$ ano).

Rubi, Ágata e Pérola mencionaram que os resultados das avaliações externas não coincidiram com os resultados de suas avaliações. Das professoras participantes da nossa pesquisa somente Esmeralda concordou com as avaliações externas, afirmando que os resultados correspondem sempre com suas avaliações "Eu concordo com avaliações externas porque assim eu fico sabendo, na realidade, o que meus alunos sabem. Muitas vezes você acha que o aluno está bom e quando vai perceber [...] (EI, ESMERALDA - Prof. a $3^{\circ}$ ano).

Segundo Freitas (2009, p. 48):

As políticas de avaliação centralizadas se esquecem que não basta o dado do desempenho do aluno ou do professor coletado em um teste ou questionário e seus fatores associados. É preciso que o dado seja "reconhecido" como "pertencendo" à escola. Medir propicia um dado com vistas ao futuro. Isso implica a existência de um processo interno de reflexão nas escolas [...] (FREITAS, 2009, p. 48, grifo do autor).

Parece-nos ser esse mais um motivo que levou as professoras a não atribuírem sentido às avaliações, pois elas não reconheceram os resultados da avaliação ADEPE como pertencendo à escola, na medida em que os resultados não correspondem com a avaliação que fazem de seus alunos.

Segundo as professoras, não haveria necessidade da avaliação ADEPE no primeiro ciclo em Mato Grosso, uma vez que os alunos já realizam todos os anos a Provinha Brasil, cujos resultados se encontram disponíveis no Portal INEP.

Entre as duas provas, fazendo um paralelo entre elas, eu acho que não era necessário à do Estado porque a PROVINHA BRASIL já faz essa avaliação. Porque como já tem uma certa frequência de ano que ela é feita, não há muitas mudanças de um ano para outro na PROVINHA BRASIL, são sempre umas adaptações que fazem diferença para as crianças. Eu acho que a PROVINHA BRASIL atendeu mais a realidade do ensino hoje do que essa que foi pelo Estado, porque a do Estado, o peso dela foi maior em outras questões, eram questões mais abstratas, era para criança que já lê e já escreve, e a PROVINHA BRASIL já me pareceu mais para construção do conhecimento, ela priorizou mais a construção do conhecimento. (EI, ÁGATA Prof. ${ }^{\mathrm{a}}{ }^{\mathrm{o}}$ ano).

Portanto, consideramos que a formação continuada PEIP, focada nas avaliações externas, foi um encaminhamento equivocado desde o princípio, principalmente quando passou a ser planejada e conduzida desconsiderando as necessidades das unidades escolares. Além 
disso, a demora e o desencontro de formações, informações e orientações anteciparam o fracasso da formação que já era previsto, devido a demasiada importância dada às avaliações externas, desconsiderando as avaliações da aprendizagem realizadas pelos docentes.

Esse modelo de formação deixa consequências no processo de ensino-aprendizagem, porque as professoras manifestaram o dilema que vivenciaram a se verem na situação de ensinar focando nos resultados e não no processo.

\begin{abstract}
Eu estou fazendo muito isso esse ano, agora é aula de matemática, eu quero atender tal e tal objetivo. Eu sofri com esse conflito, porque a gente tenta fazer um trabalho interdisciplinar, [...] Mas agora, com essa nova roupagem de avaliação do sistema a gente está meio que retrocedendo. [...] Então a minha visão, o meu foco de avaliação está interferindo na minha metodologia [...] parece que eu estou fazendo algo errado. Então, quando eu trabalhava mais interdisciplinar, eu colocava as crianças mais para ler, para questionar, o que que está pedindo o exercício [...] Então as vezes eu me pego pulando um processo que poderia ser bem interessante. (EC, ÁGATA - Prof. ${ }^{a}{ }^{\circ}$ ano).
\end{abstract}

Apesar da instituição formadora indicar um movimento de aprendizagem da docência que seja mais significativa para as crianças, as alfabetizadoras acabam tendo que agir segundo a política pública educacional do Estado, caminhando em desacordo daquilo que acreditam, e é perceptível o pesar na voz da professora Ágata ao dizer "eu acabo pulando um processo que poderia ser bem interessante" (EC, ÁGATA - Prof ${ }^{a} .2^{\circ}$ ano).

\title{
5 CONSIDERAÇÕES FINAIS
}

Ao finalizar a pesquisa constatamos que o PEIP não foi efetivamente implementado e as contribuições foram ínfimas, na perspectiva dos participantes. Pela maneira como foi proposta, a formação já iniciou desacreditada pelos docentes e gestores escolares, o que nos faz considerar que ainda há muito a se avançar para que a formação continuada efetivamente promova o desenvolvimento profissional. Ensinar é uma atividade complexa e complexo também é o processo da formação e do desenvolvimento da docência. Há de se considerar que o desenvolvimento profissional abarca a história de vida dos profissionais, a formação inicial, as experiências escolares, as motivações, a cultura escolar e as condições objetivas de trabalho, dentre outros aspectos, e que precisa ser configurada a partir das necessidades pessoais, profissionais e institucionais.

\section{REFERÊNCIAS}

AVALIAÇÃO DIAGNÓSTICA DO ENSINO PÚBLICO ESTADUAL DE MATO GROSSO (ADEPE-MT). Matemática: $2^{\circ}$ e $4^{\circ}$ Anos do Ensino Fundamental. Universidade Federal de Juiz de Fora, Faculdade de Educação, CAEd. ADEPE-MT, v. 1, 2016. 
COSTA, Marilda Oliveira; GENTIL, Heloisa Salles; AMARAL, Maria Clara Ede. Estado, Mercado e a Privatização "oculta" da Educação: o caso de Mato Grosso. In XI SEMINÁRIO INTERNACIONAL DE LA RED ESTRADO, 11, 2016, México-DF. Anais... México: Universidad Pedagógica Nacional de México, 2016, p. 1-17.

DAY, Christopher. Desenvolvimento profissional de professores. Os desafios da aprendizagem permanente. Porto: Porto Editora, 2001.

DINIZ-PEREIRA, Júlio Emílio. Desenvolvimento profissional docente: um conceito em disputa. In: IMBERNON, Francisco; NETO, Alexandre Shigunov; FORTUNATO, Ivan; (Org.). Formação permanente de professores: experiências ibero-americanas. São Paulo: Edições Hipótese, 2019.

FIORENTINI, Dario. Alguns modos de ver e conceber o ensino da Matemática no Brasil. Zetetiké: Revista de Educação Matemática. Campinas, SP, v. 3, n. 4, p. 1-38, nov. 1995. Disponível em: https://periodicos.sbu.unicamp.br/ojs/index.php/zetetike/article/view/8646877/15035. Acesso em: 22 de jan. 2017.

FREITAS, Luiz Carlos et al. Avaliação educacional: caminhando pela contramão. Petrópolis, RJ: Editora Vozes Limitada, 2009.

GATTI, Bernadete Angelina; BARRETO, Elba Siqueira de Sá. Professores do Brasil: impasses e desafios. Brasília: UNESCO, 2009.

IMBERNÓN, Francisco. Formação continuada de professores. Tradução Juliana dos Santos Padilha. Porto Alegre: Artmed, 2010.

MATO GROSSO, Secretaria do Estado de Mato Grosso. Portaria ${ }^{\circ} 161$, de 14 de abril de 2016. Diário Oficial do Estado de Mato Grosso. Cuiabá, 2016.

MORETTI, Vanessa Dias. Educação Matemática nos anos iniciais do Ensino Fundamental: Princípios e práticas pedagógicas. São Paulo: Cortez, 2015.

MORETTI, Vanessa Dias. Professores de Matemática e atividade de ensino: uma perspectiva histórico-cultural para a formação docente. 2007. 207 f. São Paulo: Tese (Doutorado em Educação) - Universidade Federal de São Paulo, São Paulo, 2007.

MOURA, Manoel Oriosvaldo de. A atividade de ensino como ação formadora. In: CASTRO, Amélia Domingues de; CARVALHO, Ana Maria Pessoa de. (Orgs.). Ensinar a Ensinar: didática para a escola fundamental e média. São Paulo: Pioneira Thomson Learning, 2002.

MOURA, Manoel Oriosvaldo de. Educar com a Matemática: saber específico e saber pedagógico. Revista Educación y Pedagogía, v. 23, n. 59, enero-abril, 2011. Disponível em <http:// aprendeenlinea.udea.edu.co/revistas/index.php/revistaeyp/article/view/8691/8005>. Acesso em 10 de ago. de 2017.

STAKE, Robert E. A Arte da Investigação com Estudo de Caso. $3^{\circ}$ ed. Fundação Calouste Gulbenkian: Lisboa. 2012.

Recebido em: 15 de outubro de 2019 .

Aprovado em: 13 de dezembro de 2019. 